\title{
A systematic review and meta-analyses of the relationship between glutathione S- transferase gene polymorphisms and renal cell carcinoma susceptibility
}

\author{
Zhiqing Zhong ${ }^{1+}$, Hongyan $\mathrm{Li}^{2+}$, Hongzhen Zhong $^{1+} \mathbb{B}^{\text {, Tianbiao Zhou }}{ }^{1 *}$, Weiji Xie ${ }^{1}$ and Zhijun Lin ${ }^{1}$
}

\begin{abstract}
Background: Association of GSTM1- and GSTT1-null genotypes, GSTP1 A/G gene polymorphism with renal cell carcinoma (RCC) susceptibility was detected, and the relationship between the GSTM1/GSTT1-null genotype and clinical TNM stages of RCC was assessed, using meta-analysis method.

Methods: Association investigations according to eligibility criteria were searched and identified from the databases of Cochrane Library, PubMed, and Embase from establishment time of databases to July 1, 2017, and eligible reports were analyzed by meta-analysis. 95\% confidence intervals (CI) were also detected, and odds ratios (OR) was used to express the results for dichotomous data.

Results: This meta-analysis indicated that there was no an association between GSTM1-null genotype, GSTT1-null genotype, GSTP1 A/G gene polymorphism and RCC risk in the overall population of Caucasians or Asians. The dual GSTM1-GSTT1-null genotype was also not associated with RCC in the overall population of Caucasians. Interestingly, there was an association between the dual GSTM1-GSTT1-null genotype and the susceptibility of RCC in Asians. Relationship of the GSTM1-null genotype with clinical TNM stage of RCC was not observed in the overall population of Asians or Caucasians. In this meta-analysis, no association between the GSTT1-null genotype and clinical TNM stage of RCC was observed in Caucasians or Asians. Interestingly, GSTT1-null genotype was detected to be associated with the clinical TNM stages in patients with RCC in the overall population.

Conclusion: The dual GSTM1-GSTT1-null genotype is detected to be associated with the onset of RCC in Asians, and there is an association between the GSTT1-null genotype and the clinical TNM stages in patients with RCC in the overall population.
\end{abstract}

Keywords: Renal cell carcinoma, GSTM1, GSTT1, GSTP1, Gene polymorphism, Meta-analysis

\section{Background}

Renal cell carcinoma (RCC) is associated with high mortality, accounts for approximately $80-85 \%$ of all renal tumors, and is the most common type of adult kidney cancer with poor prognosis [1]. Approximately $30 \%$ RCC patients already have metastatic lesions upon initial diagnosis [2]. Renal cell carcinoma (RCC) is highly resistant

\footnotetext{
* Correspondence: zhoutb@aliyun.com

†Zhiqing Zhong, Hongyan Li and Hongzhen Zhong contributed equally to this work.

${ }^{1}$ Department of Nephrology, the Second Affiliated Hospital of Shantou University Medical College, No. 69 Dongsha Road, Shantou 515041, China Full list of author information is available at the end of the article
}

to both chemotherapy and radiotherapy [3]. Early diagnosis of patients with RCC would significantly improve their prognosis and quality of life [4-6]. The incidence of survival is very low, since most RCC patients have developed metastases beyond the kidney tissue when the RCC is diagnosed $[4,7,8]$. Early diagnosis for the disease of RCC is very difficult, and the RCC etiology is complicated $[4,8]$. Gene polymorphisms are reported to be associated with susceptibility of many diseases [9-13]. Current evidence also shows some gene polymorphisms to be associated with RCC risk [14-17].

(c) The Author(s). 2018 Open Access This article is distributed under the terms of the Creative Commons Attribution 4.0 International License (http://creativecommons.org/licenses/by/4.0/), which permits unrestricted use, distribution, and reproduction in any medium, provided you give appropriate credit to the original author(s) and the source, provide a link to the Creative Commons license, and indicate if changes were made. The Creative Commons Public Domain Dedication waiver (http://creativecommons.org/publicdomain/zero/1.0/) applies to the data made available in this article, unless otherwise stated. 
The glutathione S-transferases (GSTs) is a family of isozymes including GSTM1, GSTT1, and GSTP1 classes, and can catalyze the glutathione to detoxify xenobiotics $[18,19]$. GSTs conjugate glutathione (GSH), a scavenger peptide, with electrophilic compounds [20, 21], and are known to play a pivotal role in the detoxification of some potential carcinogens [22, 23]. It has also been suggested that certain GST gene polymorphisms, leading to altered detoxification activity, predispose individuals to certain cancers, such as prostate cancer, hepatocellular carcinoma, and colorectal cancer [24-26].

Previously, most epidemiologic investigations have detected a relationship between the GSTM1/GSTT-null phenotype, the GSTP1 A/G gene polymorphism, and RCC risk. But, the current evidence is inadequate, for the reason that sparseness of data or inconsistencies among these reported investigations. This meta-analysis was conducted to assess whether the null genotype of GSTM1/GSTT1 and the GSTP1 A/G gene polymorphism are associated with RCC susceptibility by ethnicity, and whether there is an association between the null genotype of GSTM1/GSTT1 and clinical TNM stages in patients with RCC by ethnicity, due to the fact that the genotype distributions of the different populations might differ from each other $[27,28]$. We also evaluated the publication bias for the relationship between the GSTM1-null genotype, GSTT1-null genotype, dual GSTM1/GSTT1-null genotype, and GSTP1 A/G gene polymorphism and RCC risk for the overall population.

\section{Methods}

\section{Search strategy}

Retrieval of relevant published articles were conducted in the electronic databases of Cochrane Library, PubMed, and Embase from establishment time of databases to July 1, 2017, and eligible investigations were recruited for our meta-analysis. Key subjects for retrieval consisted of ("glutathione S-transferases" OR “GSTs" OR “GSTM1" OR "GSTT1" OR "GSTP1") and ("renal cell carcinoma" OR "renal cancer" OR "RCC"). Additional reports were also recruited through references which were cited in the included investigations, and references of retrieved articles from previous meta-analyses were also inspected.

\section{Inclusion criteria and exclusion criteria Inclusion criteria}

(1) prospective study, case-control study, and cross-sectional study; (2) there should be two comparison groups (RCC vs. control); (3) the endpoint had to be RCC; (4) the study should provide detailed data for the genotype distribution.

\section{Exclusion criteria}

(1) primary results were not on GSTM1, GSTT1, GSTP1 or outcome; (2) review articles, case reports and editorials; (3) investigated the effect of GST gene expression on disease.

\section{Quality appraisal}

In order to evaluate the quality of the recruited investigations that met the inclusive criteria mentioned above, a quality score criteria based on seven aspects of a genetic association investigations was used (Additional file 1: Table S1). The quality score form was instituted by Thakkinstian et al. in 2005 [29]. Its range of this form spanned from zero (the worst quality) to 12 (the best quality). Investigations were categorized to be "high quality" when the quality score was more than seven; otherwise, studies were regarded as "low quality". Quality appraisal was implemented by two researchers who were independently responsible for the literature retrieval, and discussions were held until every aspect was entirely consistent by comparison.

\section{Data extraction and data synthesis}

The following information from each eligible study was excerpted by two investigators independently: the surname of first author, publication year and the sample size of RCC cases and controls for GSTM1, GSTT1, and GSTP1 genotypes. Frequencies of genotypes for GSTM1, GSTT1 and GSTP1 were calculated for each case group and control group. The results were compared, and discussion was performed when there was disagreement. Consistency of data extracted by the two researchers was tested and any disagreement was resolved through discussion.

\section{Statistical analysis}

All statistical analyses were performed using Cochrane Review Manager Version 5.3 (Cochrane Library, UK). Fixed-effect model (Mantel-Haenszel method) was used to estimate the pooled statistic. The heterogeneity among the included studies was detected using $I^{2}$. On the other hand, when the $P$-value from the heterogeneity test was less than 0.1, a random effects model (DerSimonian-Laird method) was conducted. Odds ratios (OR) were used for results of dichotomous data, and 95\% confidence intervals $(\mathrm{CI})$ were also counted. A $P<0.05$ was regarded as statistical significance for the pooled OR. Publication bias was graphically judged from the Begg adjusted rank correlation test [30] and the Egger regression asymmetry test [31], when the number of the included studies was more than six. 


\section{Results}

\section{Study characteristics}

Fifteen investigations [32-46] were recruited into our meta-analysis to assess the association between the GSTM1-null genotype and the susceptibility of RCC (Fig. 1 and Table 1). Data was extracted by the sequences of the surname of first author, publication year and the sample size of RCC cases and controls for the GSTM1 genotype (Table 1). The 15 included reports contained 3782 cases and 5223 controls. The average GSTM1-null genotype distribution frequency in controls was $49.83 \%$, and the average genotype distribution frequency of the GSTM1-null genotype in patients with $\mathrm{RCC}$ was $48.63 \%$, indicating the average GSTM1-null genotype distribution frequency in RCC patients was similar to that in the control group (control/RCC =1.02), suggesting that the GSTM1-null genotype was unrelated to RCC.
Fifteen studies [32-46] were recruited into our meta-analysis to detect the association of the GSTT1-null genotype with RCC susceptibility (Fig. 1 and Table 1). Those 15 investigations contained 3735 cases and 5179 controls. The average GSTT1-null genotype distribution frequency in controls was $23.02 \%$ and the average GSTT1-null genotype distribution frequency in $\mathrm{RCC}$ cases was $24.62 \%$. Therefore, the average distribution frequency of the GSTT1-null genotype in control group was similar to that in cases (control/RCC $=0.94$ ), suggesting that the GSTT1-null genotype was also unrelated to RCC.

Nine studies [32, 34, 36, 38, 41-45] were recruited into our meta-analysis to assess the relationship of the dual-null genotype, of individuals lacking both GSTM1 and GSTT1, and the susceptibility of RCC (Fig. 1 and Table 1). The nine investigations contained 2679 cases and 3589 controls. The average GSTM1-GSTT1

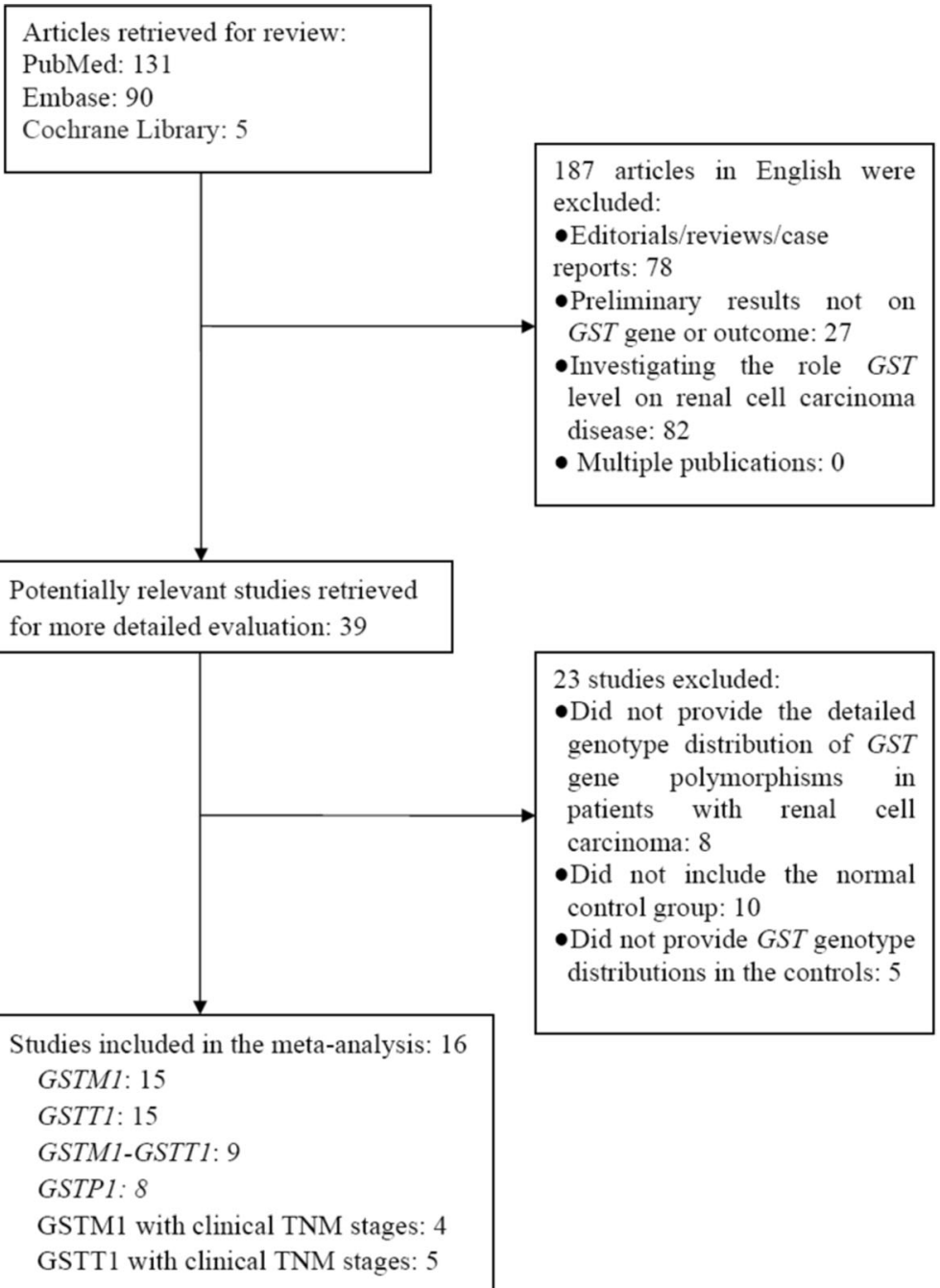

Fig. 1 Flow chart of the study search and selection 
Table 1 Characteristics of studies evaluating the effects of GSTM1 and GSTT1 null genotypes on RCC risk

\begin{tabular}{|c|c|c|c|c|c|c|c|c|c|c|c|}
\hline \multirow{2}{*}{$\begin{array}{l}\text { Gene } \\
\text { Locus }\end{array}$} & \multirow[t]{2}{*}{ Author, Year } & \multirow[t]{2}{*}{ Country } & \multirow[t]{2}{*}{ Ethnicity } & \multirow[t]{2}{*}{ Source of controls } & \multirow{2}{*}{$\begin{array}{l}\text { Quality } \\
\text { Score }\end{array}$} & \multicolumn{3}{|c|}{ Case } & \multicolumn{3}{|c|}{ Control } \\
\hline & & & & & & - & + & Total & - & + & Total \\
\hline \multirow[t]{15}{*}{ GSTM1 } & Bruning 1997 & Germany & Caucasian & Population-based & 6 & 18 & 27 & 45 & 31 & 17 & 48 \\
\hline & Longuemaux 1999 & France & Caucasian & Hospital-based & 8 & 89 & 84 & 173 & 117 & 94 & 211 \\
\hline & Sweeney 2000 & USA & Mix & Population-based & 9 & 63 & 63 & 126 & 255 & 250 & 505 \\
\hline & Buzio 2003 & Italy & Caucasian & Hospital-based & 8 & 50 & 50 & 100 & 108 & 92 & 200 \\
\hline & Moore 2007 & Europe & Caucasian & Hospital-based & 9 & 424 & 487 & 911 & 555 & 677 & 1232 \\
\hline & Wiesenhütter 2007 & Germany & Caucasian & Hospital-based & 8 & 51 & 47 & 98 & 167 & 157 & 324 \\
\hline & Karami 2008 & Europe & Caucasian & Hospital-based & 9 & 303 & 321 & 624 & 433 & 454 & 887 \\
\hline & Coric 2010 & Serbia & Caucasian & Hospital-based & 8 & 46 & 30 & 76 & 86 & 96 & 182 \\
\hline & De Martino 2010 & Austria & Caucasian & Hospital-based & 8 & 80 & 67 & 147 & 59 & 53 & 112 \\
\hline & Ahmad 2012 & India & Asian & Population-based & 11 & 102 & 94 & 196 & 116 & 134 & 250 \\
\hline & Salinas-Sanchez 2012 & Spain & Caucasian & Hospital-based & 6 & 57 & 76 & 133 & 78 & 115 & 193 \\
\hline & Jia 2014 & China & Asian & Population-based & NC & 22 & 28 & 50 & 30 & 30 & 60 \\
\hline & Coric 2016 & Serbia & Caucasian & Hospital-based & 8 & 87 & 109 & 196 & 137 & 137 & 274 \\
\hline & Abid 2016 & Pakistan & Asian & Hospital-based & 8 & 224 & 378 & 602 & 171 & 248 & 419 \\
\hline & Coric 2017 & Serbia & Caucasian & Hospital-based & 8 & 169 & 136 & 305 & 163 & 163 & 326 \\
\hline \multirow[t]{15}{*}{ GSTT1 } & Bruning 1997 & Germany & Caucasian & Population-based & 6 & 3 & 42 & 45 & 11 & 37 & 48 \\
\hline & Longuemaux 1999 & France & Caucasian & Hospital-based & 8 & 25 & 148 & 173 & 40 & 171 & 211 \\
\hline & Sweeney 2000 & USA & Mix & Population-based & 9 & 36 & 90 & 126 & 93 & 412 & 505 \\
\hline & Buzio 2003 & Italy & Caucasian & Hospital-based & 8 & 11 & 89 & 100 & 35 & 165 & 200 \\
\hline & Moore 2007 & Europe & Caucasian & Hospital-based & 9 & 167 & 744 & 911 & 209 & 1023 & 1232 \\
\hline & Wiesenhütter 2007 & Germany & Caucasian & Hospital-based & 8 & 19 & 79 & 98 & 59 & 265 & 324 \\
\hline & Karami 2008 & Europe & Caucasian & Hospital-based & 9 & 129 & 499 & 628 & 161 & 752 & 913 \\
\hline & Coric 2010 & Serbia & Caucasian & Hospital-based & 8 & 21 & 55 & 76 & 52 & 130 & 182 \\
\hline & De Martino 2010 & Austria & Caucasian & Hospital-based & 8 & 27 & 120 & 147 & 23 & 89 & 112 \\
\hline & Salinas-Sanchez 2012 & Spain & Caucasian & Hospital-based & 6 & 22 & 110 & 132 & 25 & 138 & 163 \\
\hline & Ahmad 2012 & India & Asian & Population-based & 11 & 125 & 71 & 196 & 106 & 144 & 250 \\
\hline & Jia 2014 & China & Asian & Population-based & NC & 30 & 18 & 48 & 25 & 35 & 60 \\
\hline & Coric 2016 & Serbia & Caucasian & Hospital-based & 8 & 44 & 152 & 196 & 71 & 203 & 274 \\
\hline & Abid 2016 & Pakistan & Asian & Hospital-based & 8 & 72 & 482 & 554 & 49 & 330 & 379 \\
\hline & Coric 2017 & Serbia & Caucasian & Hospital-based & 8 & 79 & 226 & 305 & 89 & 237 & 326 \\
\hline \multirow[t]{9}{*}{ GSTM1-GSTT1 } & Bruning 1997 & Germany & Caucasian & Population-based & 6 & 1 & 44 & 45 & 6 & 42 & 48 \\
\hline & Sweeney 2000 & USA & Mix & Population-based & 9 & 17 & 109 & 126 & 49 & 456 & 505 \\
\hline & Moore 2007 & Europe & Caucasian & Hospital-based & 9 & 82 & 829 & 911 & 99 & 1133 & 1232 \\
\hline & Karami 2008 & Europe & Caucasian & Hospital-based & 9 & 363 & 260 & 623 & 508 & 372 & 880 \\
\hline & Salinas-Sanchez 2012 & Spain & Caucasian & Hospital-based & 6 & 7 & 126 & 133 & 8 & 185 & 193 \\
\hline & Ahmad 2012 & India & Asian & Population-based & 11 & 71 & 125 & 196 & 54 & 196 & 250 \\
\hline & Jia 2014 & China & Asian & Population-based & NC & 14 & 34 & 48 & 10 & 50 & 60 \\
\hline & Coric 2016 & Serbia & Caucasian & Hospital-based & 8 & 24 & 20 & 44 & 36 & 35 & 71 \\
\hline & Abid 2016 & Pakistan & Asian & Hospital-based & 8 & 29 & 524 & 553 & 17 & 333 & 350 \\
\hline
\end{tabular}

NC not clear

dual-null genotype distribution frequency in cases with RCC was $23.71 \%$ compared to the average frequency of $20.66 \%$ in the controls. The average dual-null genotype of GSTM1-GSTT1 distribution frequency in RCC patients was slightly increased when compared with that in control group $(\mathrm{RCC} /$ control $=1.15)$. 
Eight studies [33, 34, 36, 37, 41, 44, 46, 47] were included in our study to detect the association of the null genotype of GSTP1 with the susceptibility of RCC (Fig. 1 and Table 2). These 8 investigations contained 2197 cases and 3323 controls. The average A allele distribution frequency in controls was $70.44 \%$, and the average A allele distribution frequency in RCC cases was $69.11 \%$. The average A allele distribution frequency of GSTP1 in control group was similar when compared with that in the RCC group (control/RCC $=1.02$ ), suggesting a lack of association of the GSTP1 A allele with RCC.

Four studies [34, 40, 41, 45] were included in our meta-analysis to detect the relationship of GSTM1 with clinical TNM stage of RCC (Fig. 1 and Table 3). Those four investigations contained 501 cases and 423 controls. The average GSTM1-null genotype distribution frequency in stage I+ II was $47.33 \%$, and the average GSTM1-null genotype distribution frequency in stage III + IV was 55.76\%. The average GSTM1-null genotype distribution frequency in stage I + II was slightly reduced than that in stage III + IV $(\mathrm{I}+\mathrm{II} / \mathrm{III}+\mathrm{IV}=0.85)$.

Five studies [34, 40-42, 45] were recruited into this meta-analysis to assess the association between GSTT1 and clinical TNM stages of RCC (Fig. 1 and Table 3). Those five studies contained 570 cases and 434 controls. The average GSTT1-null genotype distribution frequency in stage I + II was $37.15 \%$, compared to the average frequency of $49.1 \%$ in stage III + IV patients. The average GSTT1-null genotype distribution frequency in stage I+ II was notably reduced than the average GSTT1-null genotype distribution frequency in stage III + IV $(\mathrm{I}+\mathrm{II} / \mathrm{III}+\mathrm{IV}=0.76)$.

\section{Relationship between the GSTM1-null genotype and the susceptibility of RCC}

The GSTM1-null genotype was found to be not associated with RCC susceptibility in the collective populations, Asians and Caucasians, hospital-based controls, or population-based controls (collective populations: $\quad \mathrm{OR}=1.00, \quad 95 \% \quad \mathrm{CI}: \quad 0.92-1.09, \quad P=0.91$;
Caucasians: $\mathrm{OR}=1.02, \quad 95 \%$ CI: $0.92-1.12, \quad P=0.72$; Asians: $\quad \mathrm{OR}=0.95, \quad 95 \% \quad \mathrm{CI}: \quad 0.78-1.17, \quad P=0.65$; hospital-based controls: $\mathrm{OR}=1.01,95 \% \mathrm{CI}: 0.92-1.11$, $P=0.85 ;$ population-based controls: $\mathrm{OR}=0.87,95 \%$ CI: $0.57-1.33, P=0.52$; Fig. 2 for the overall population; Table 4). When only the high-quality investigations were recruited for meta-analysis, this association was also not found $(\mathrm{OR}=1.02$, 95\% CI: $0.93-1.11, P=0.72$; Table 4).

\section{Relationship between the GSTT1-null genotype and the susceptibility of RCC}

Association of GSTT1 null genotype with RCC risk was not found in the overall population, Caucasians and Asians, hospital-based controls, population-based controls (overall population: $\mathrm{OR}=1.09,95 \% \mathrm{CI}$ : 0.90 1.33, $P=0.38$; Caucasians: $\mathrm{OR}=1.00,95 \% \mathrm{CI}: 0.88$ 1.13, $P=0.97$; Asians: $\mathrm{OR}=1.73,95 \% \mathrm{CI}: 0.95-3.28$, $P=0.09$; hospital-based controls: $\mathrm{OR}=1.01,95 \% \mathrm{CI}$ : $0.90-1.14, P=0.84$; population-based controls: $\mathrm{OR}=$ 1.62, 95\% CI: $0.90-2.91, P=0.11$; Fig. 3 for the overall population; Table 4). When only the high-quality investigations were included for meta-analysis, an association was also not found (OR $=1.09,95 \%$ CI: $0.90-1.32$, $P=0.39$; Table 4).

\section{Association of the dual GSTM1-GSTT1-null genotype with the susceptibility of RCC}

There was no an association between the dual-null genotype of individuals lacking both GSTM1- and GSTT1 and RCC risk in the overall population, Caucasians, or hospital-based controls (overall population: $\mathrm{OR}=1.26,95 \% \mathrm{CI}: 1.00-1.59, P=0.05$; Caucasians: $\mathrm{OR}=1.05,95 \% \mathrm{CI}: 0.89-1.23, P=0.58$; hospital-based controls: $\mathrm{OR}=1.07,95 \% \mathrm{CI}$ : $0.91-$ $1.25, P=0.43$; Fig. 4 for the overall population; Table 4). When only the high-quality studies were recruited for meta-analysis, this association was also not found $(\mathrm{OR}=1.17,95 \% \mathrm{CI}: 1.01-1.36, P=0.03$; Table 4). However, stratification into Caucasians

Table 2 Characteristics of studies evaluating the effects of GSTP1 gene polymorphism on RCC risk

\begin{tabular}{|c|c|c|c|c|c|c|c|c|c|c|c|c|}
\hline \multirow[t]{2}{*}{ Author, Year } & \multirow[t]{2}{*}{ Country } & \multirow[t]{2}{*}{ Ethnicity } & \multirow{2}{*}{$\begin{array}{l}\text { Source of } \\
\text { controls }\end{array}$} & \multirow{2}{*}{$\begin{array}{l}\text { Quality } \\
\text { Score }\end{array}$} & \multicolumn{4}{|l|}{ Case } & \multicolumn{4}{|c|}{ Control } \\
\hline & & & & & $\overline{\mathrm{AA}}$ & $A G$ & GG & $\overline{\text { Total }}$ & $\overline{\mathrm{AA}}$ & $A G$ & GG & $\overline{\text { Total }}$ \\
\hline Longuemaux 1999 & France & Caucasian & Hospital-based & 8 & 71 & 67 & 22 & 160 & 93 & 75 & 21 & 189 \\
\hline Sweeney 2000 & USA & Mix & Population-based & 9 & 58 & 56 & 16 & 130 & 213 & 216 & 62 & 491 \\
\hline Wiesenhütter 2007 & Germany & Caucasian & Hospital-based & 8 & 49 & 43 & 7 & 99 & 134 & 144 & 47 & 325 \\
\hline Moore 2007 & Europe & Caucasian & Hospital-based & 9 & 425 & 390 & 95 & 910 & 577 & 548 & 107 & 1232 \\
\hline Wang 2011 & China & Asian & Hospital-based & 9 & 143 & 55 & 9 & 207 & 173 & 54 & 9 & 236 \\
\hline Ahmad 2012 & India & Asian & Population-based & 11 & 71 & 99 & 26 & 196 & 126 & 103 & 21 & 250 \\
\hline Coric 2016 & Serbia & Caucasian & Hospital-based & 8 & 44 & - & - & 194 & 115 & - & - & 274 \\
\hline Coric 2017 & Serbia & Caucasian & Hospital-based & 8 & 74 & - & - & 301 & 141 & - & - & 326 \\
\hline
\end{tabular}


Table 3 Characteristics of studies evaluating the effects of GSTM1 and GSTT1 null genotypes on clinical TNM stages of RCC

\begin{tabular}{|c|c|c|c|c|c|c|c|c|c|c|c|}
\hline \multirow{2}{*}{$\begin{array}{l}\text { Gene } \\
\text { Locus }\end{array}$} & \multirow[t]{2}{*}{ Author, Year } & \multirow[t]{2}{*}{ Country } & \multirow[t]{2}{*}{ Ethnicity } & \multirow{2}{*}{$\begin{array}{l}\text { Source of } \\
\text { controls }\end{array}$} & \multirow{2}{*}{$\begin{array}{l}\text { Quality } \\
\text { Score }\end{array}$} & \multicolumn{3}{|c|}{ Stage I+ II } & \multicolumn{3}{|c|}{ Stage III + IV } \\
\hline & & & & & & - & + & Total & - & + & Total \\
\hline \multirow[t]{4}{*}{ GSTM1-TNM } & Sweeney 2000 & USA & Mix & Population-based & 9 & 50 & 55 & 105 & 15 & 8 & 23 \\
\hline & De Martino 2010 & Austria & Caucasian & Hospital-based & 8 & 45 & 29 & 74 & 35 & 38 & 73 \\
\hline & Ahmad 2012 & India & Asian & Population-based & 11 & 53 & 77 & 130 & 49 & 17 & 66 \\
\hline & Abid 2016 & Pakistan & Asian & Hospital-based & 8 & 77 & 115 & 192 & 93 & 168 & 261 \\
\hline \multirow[t]{5}{*}{ GSTT1-TNM } & Sweeney 2000 & USA & Mix & Population-based & 9 & 29 & 76 & 105 & 6 & 17 & 23 \\
\hline & De Martino 2010 & Austria & Caucasian & Hospital-based & 8 & 12 & 62 & 74 & 15 & 58 & 73 \\
\hline & Ahmad 2012 & India & Asian & Population-based & 11 & 72 & 58 & 130 & 53 & 13 & 66 \\
\hline & Salinas-Sanchez 2012 & Spain & Caucasian & Hospital-based & 6 & 39 & 40 & 79 & 25 & 11 & 36 \\
\hline & Abid 2016 & Pakistan & Asian & Hospital-based & 8 & 21 & 161 & 182 & 36 & 200 & 236 \\
\hline
\end{tabular}

and Asians revealed that the dual GSTM1-GSTT1-null genotype was associated with the onset of RCC in Asians, when compared to population-based controls (Asians: $\mathrm{OR}=1.72$, 95\% CI: 1.24-2.38, $P=0.001$; population-based controls: OR $=1.70,95 \%$ CI: 1.25-2.32, $P=0.0007$; Table 4).

\section{Association between the GSTP1 a/G gene polymorphism and RCC susceptibility}

The GSTP1 A/G gene polymorphism was not associated with RCC risk in the overall population, Asians and Caucasians, hospital-based controls, or population-based controls (overall population: A allele: $\mathrm{OR}=0.93,95 \% \mathrm{CI}$ : $0.77-1.11, P=0.41 ;$ AA genotype: $\mathrm{OR}=0.74,95 \% \mathrm{CI}$ : $0.55-1.00, P=0.05$; GG genotype: $\mathrm{OR}=1.14,95 \% \mathrm{CI}$ : $0.93-1.14, P=0.22$; Table 4 ). When only the high-quality studies were recruited for the meta-analysis, this relationship was also not found (A allele: $\mathrm{OR}=0.93,95 \% \mathrm{CI}$ : $0.77-1.11, P=0.41 ;$ AA genotype: $\mathrm{OR}=0.74,95 \% \mathrm{CI}$ : $0.55-1.00, P=0.05$; GG genotype: $\mathrm{OR}=1.14,95 \% \mathrm{CI}$ : 0.93-1.14, $P=0.22$; Table 4).
Relationship between the GSTM1-null genotype and clinical TNM stages of RCC

GSTM1-null genotype was not associated with the clinical TNM stages of RCC in the overall population, Caucasians, Asians, or hospital-based controls (overall population: $\mathrm{OR}=0.72$, 95\% CI: $0.30-1.70, P=0.45$; Caucasians: $\mathrm{OR}=1.68,95 \% \mathrm{CI}: 0.88-3.24, P=0.12$; Asians: $\mathrm{OR}=0.55,95 \%$ CI: 0.11-2.70, $P=0.46$; hospital-based controls: $\mathrm{OR}=1.32$, 95\% CI: 0.95-1.83, $P=0.10$; Table 4). When only the high-quality studies were recruited for meta-analysis, this association was also not found ( $\mathrm{OR}=$ 0.72, 95\% CI: $0.30-1.70, P=0.45$; Table 4). Interestingly, the GSTM1-null genotype was associated with the clinical TNM stages of RCC when the meta-analysis was compared to population-based controls $(\mathrm{OR}=0.30,95 \% \mathrm{CI}$ : 0.18-0.51, $P<0.0001$; Table 4).

\section{Association of the GSTT1-null genotype with clinical TNM stages in patients with RCC}

The GSTT1-null genotype was not associated with clinical TNM stage of RCC in Caucasians or Asians vs. population-based controls (Caucasians: $\mathrm{OR}=0.56,95 \%$

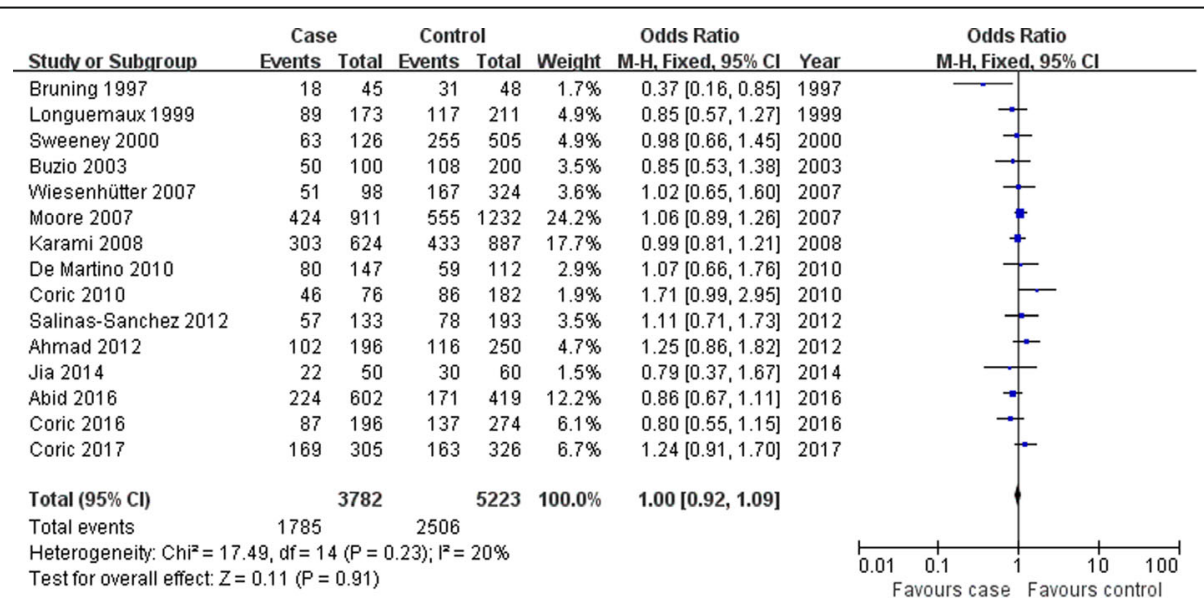

Fig. 2 Association between GSTM1 null genotype and RCC susceptibility in the overall population. Cl: confidence interval 
Table 4 Meta-analysis of the association of GSTM1- and GSTT1-null genotypes and GSTP1 with RCC risk and the relationship between GSTM1, GSTT1 and clinical TNM stages of RCC

\begin{tabular}{|c|c|c|c|c|c|c|}
\hline Genetic contrasts & Group and subgroups & Studies Number & $Q$ test $P$-value & Model selected & OR $(95 \% \mathrm{Cl})$ & $P$ \\
\hline \multicolumn{7}{|l|}{$\overline{\text { GSTM1 }}$} \\
\hline \multirow[t]{6}{*}{$-v s+$} & Overall & 15 & 0.23 & Fixed & $1.00(0.92,1.09)$ & 0.91 \\
\hline & Caucasian & 11 & 0.16 & Fixed & $1.02(0.92,1.12)$ & 0.72 \\
\hline & Asian & 3 & 0.23 & Fixed & $0.95(0.78,1.17)$ & 0.65 \\
\hline & Hospital-based & 11 & 0.43 & Fixed & $1.01(0.92,1.11)$ & 0.85 \\
\hline & Population-based & 4 & 0.06 & Random & $0.87(0.57,1.33)$ & 0.52 \\
\hline & High quality & 12 & 0.42 & Fixed & $1.02(0.93,1.11)$ & 0.72 \\
\hline \multicolumn{7}{|l|}{ GSTT1 } \\
\hline \multirow[t]{6}{*}{ - vs +} & Overall & 15 & 0.0006 & Random & $1.09(0.90,1.33)$ & 0.38 \\
\hline & Caucasian & 11 & 0.30 & Fixed & $1.00(0.88,1.13)$ & 0.97 \\
\hline & Asian & 3 & 0.005 & Random & $1.73(0.91,3.28)$ & 0.09 \\
\hline & Hospital-based & 11 & 0.68 & Fixed & $1.01(0.90,1.14)$ & 0.84 \\
\hline & Population-based & 4 & 0.01 & Random & $1.62(0.90,2.91)$ & 0.11 \\
\hline & High quality & 12 & 0.002 & Random & $1.09(0.90,1.32)$ & 0.39 \\
\hline \multicolumn{7}{|c|}{ Dual-null genotype for GSTM1/GSTT1 } \\
\hline \multirow[t]{6}{*}{$-v s+$} & Overall & 9 & 0.08 & Random & $1.26(1.00,1.59)$ & 0.05 \\
\hline & Caucasian & 5 & 0.48 & Fixed & $1.05(0.89,1.23)$ & 0.58 \\
\hline & Asian & 3 & 0.22 & Fixed & $1.72(1.24,2.38)$ & 0.001 \\
\hline & Hospital-based & 5 & 0.97 & Fixed & $1.07(0.91,1.25)$ & 0.43 \\
\hline & Population-based & 4 & 0.12 & Fixed & $1.70(1.25,2.32)$ & 0.0007 \\
\hline & High quality & 6 & 0.10 & Fixed & $1.17(1.01,1.36)$ & 0.03 \\
\hline \multicolumn{7}{|l|}{ GSTP1 } \\
\hline \multirow[t]{6}{*}{ A vs $G$} & Overall & 6 & 0.02 & Random & $0.93(0.77,1.11)$ & 0.41 \\
\hline & Caucasian & 3 & 0.06 & Random & $1.02(0.80,1.31)$ & 0.85 \\
\hline & Asian & 2 & 0.27 & Fixed & $0.72(0.58,0.90)$ & 0.003 \\
\hline & Hospital-based & 4 & 0.10 & Fixed & $0.97(0.87,1.08)$ & 0.59 \\
\hline & Population-based & 2 & 0.02 & Random & $0.82(0.52,1.29)$ & 0.39 \\
\hline & High quality & 6 & 0.02 & Random & $0.93(0.77,1.11)$ & 0.41 \\
\hline \multirow[t]{6}{*}{$A A$ vs $A G+G G$} & Overall & 8 & $<0.00001$ & Random & $0.74(0.55,1.00)$ & 0.05 \\
\hline & Caucasian & 5 & $<0.00001$ & Random & $0.72(0.46,1.13)$ & 0.15 \\
\hline & Asian & 2 & 0.19 & Fixed & $0.66(0.50,0.88)$ & 0.004 \\
\hline & Hospital-based & 6 & $<0.00001$ & Random & $0.74(0.51,1.07)$ & 0.11 \\
\hline & Population-based & 2 & 0.02 & Random & $0.77(0.41,1.42)$ & 0.40 \\
\hline & High quality & 8 & $<0.00001$ & Random & $0.74(0.55,1.00)$ & 0.05 \\
\hline \multirow[t]{6}{*}{$G G$ vs $A G+A A$} & Overall & 6 & 0.22 & Fixed & $1.14(0.93,1.40)$ & 0.22 \\
\hline & Caucasian & 3 & 0.07 & Random & $0.98(0.58,1.66)$ & 0.95 \\
\hline & Asian & 2 & 0.51 & Fixed & $1.49(0.90,2.49)$ & 0.12 \\
\hline & Hospital-based & 4 & 0.16 & Fixed & $1.10(0.87,1.40)$ & 0.43 \\
\hline & Population-based & 2 & 0.21 & Fixed & $1.26(0.83,1.91)$ & 0.28 \\
\hline & High quality & 6 & 0.22 & Fixed & $1.14(0.93,1.40)$ & 0.22 \\
\hline \multicolumn{7}{|l|}{ GSTM1-TNM } \\
\hline \multirow[t]{2}{*}{$-v s+$} & Overall & 4 & $<0.0001$ & Random & $0.72(0.30,1.70)$ & 0.45 \\
\hline & Caucasian & 1 & - & Fixed & $1.68(0.88,3.24)$ & 0.12 \\
\hline
\end{tabular}


Table 4 Meta-analysis of the association of GSTM1- and GST11-null genotypes and GSTP1 with RCC risk and the relationship between GSTM1, GSTT1 and clinical TNM stages of RCC (Continued)

\begin{tabular}{|c|c|c|c|c|c|c|}
\hline Genetic contrasts & Group and subgroups & Studies Number & $\mathrm{Q}$ test $P$-value & Model selected & OR $(95 \% \mathrm{Cl})$ & $P$ \\
\hline & Asian & 2 & $<0.0001$ & Random & $0.55(0.11,2.70)$ & 0.46 \\
\hline & Hospital-based & 2 & 0.39 & Fixed & $1.32(0.95,1.83)$ & 0.10 \\
\hline & Population-based & 2 & 0.23 & Fixed & $0.30(0.18,0.51)$ & $<0.0001$ \\
\hline & High quality & 4 & $<0.0001$ & Random & $0.72(0.30,1.70)$ & 0.45 \\
\hline \multicolumn{7}{|l|}{ GSTT1-TNM } \\
\hline \multirow[t]{6}{*}{ - vs + } & Overall & 5 & 0.19 & Fixed & $0.56(0.41,0.78)$ & 0.0006 \\
\hline & Caucasian & 2 & 0.36 & Fixed & $0.56(0.31,1.01)$ & 0.06 \\
\hline & Asian & 2 & 0.06 & Random & $0.48(0.21,1.12)$ & 0.09 \\
\hline & Hospital-based & 3 & 0.55 & Fixed & $0.64(0.42,0.97)$ & 0.03 \\
\hline & Population-based & 2 & 0.05 & Random & $0.54(0.16,1.87)$ & 0.33 \\
\hline & High quality & 4 & 0.13 & Fixed & $0.59(0.41,0.85)$ & 0.004 \\
\hline
\end{tabular}

CI: $0.31-1.01, P=0.06$; Asians: $\mathrm{OR}=0.48,95 \% \mathrm{CI}: 0.21-$ 1.12, $P=0.09$; population-based controls: $\mathrm{OR}=0.54,95 \%$ CI: $0.16-1.87, P=0.33$; Table 4$)$. When only high-quality studies were included for the meta-analysis, association of the GSTT1-null genotype with clinical TNM stage of RCC was found $(\mathrm{OR}=0.59,95 \% \mathrm{CI}: 0.41-0.85, P=$ 0.004; Table 4). Interestingly, the GSTT1-null genotype was found to be associated with the clinical TNM stages in patients with RCC in the overall population, and when the meta-analysis included hospital-based controls (overall populations: $\mathrm{OR}=0.56,95 \% \mathrm{CI}: 0.41-0.78, P=$ 0.0006; hospital-based controls: $\mathrm{OR}=0.64,95 \% \mathrm{CI}$ : 0.42-0.97, $P=0.03$; Table 4).

\section{Evaluation of publication bias}

A publication bias test was performed for the association of the GSTM1-null genotype, GSTT1-null genotype, GSTM1-null/GSTT1-null genotype, and GSTP1 A/G gene polymorphism with $\mathrm{RCC}$ risk, when compared to the overall population. No publication biases for the relationship between the GSTM1-null genotype or GSTT1-null genotype and RCC risk was determined in the overall population (GSTM1: Begg $P=0.692$, Egger $P$ $=0.400 ;$ GSTT1: Begg $P=0.166$, Egger $P=0.095$; GSTM1-null/GSTT1-null genotype: Begg $P=0.917$, Egger $P=0.628$; GSTP1 A/G gene polymorphism: Begg $P=0.902$, Egger $P=0.290$; Fig. 5).

\section{Discussion}

In this study, we found that the average GSTM1-null genotype distribution frequency in patients with RCC is similar with the average GSTM1-null genotype distribution frequency in the control group, indicating that the GSTM1-null genotype is not associated with RCC susceptibility. We performed the meta-analysis in further depth, and still found that there is no an association between null genotype for GSTM1 and RCC risk in the overall population of Caucasians and Asians, hospital-based controls, population-based controls, high-quality studies. Publication bias was also tested and

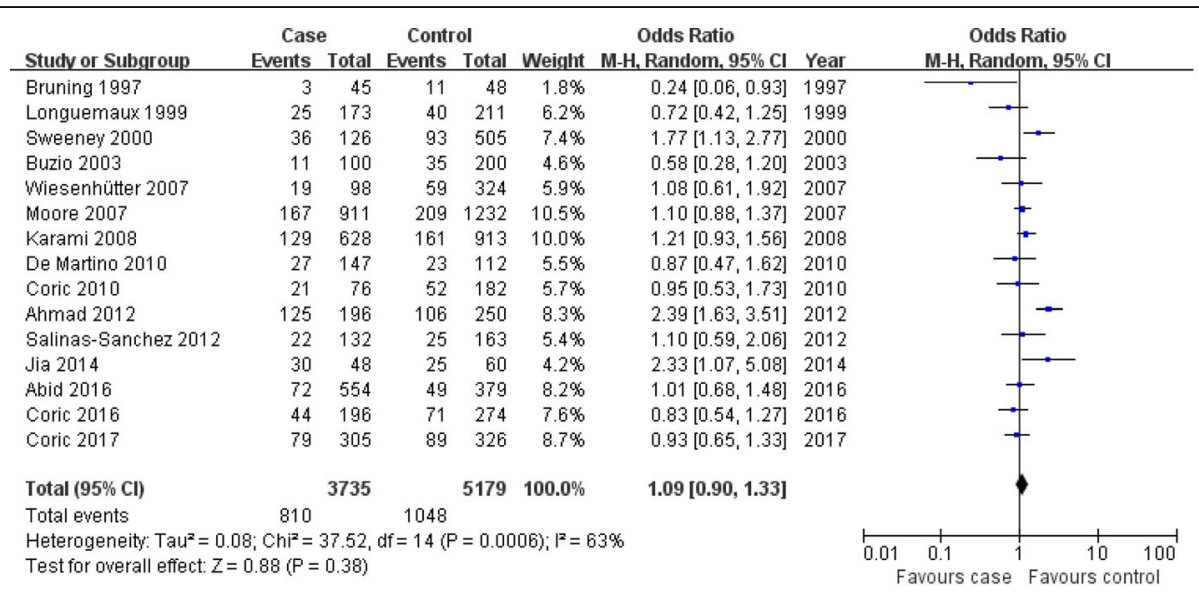

Fig. 3 Association between the GSTT1-null genotype and RCC susceptibility in the overall population. Cl: confidence interval 


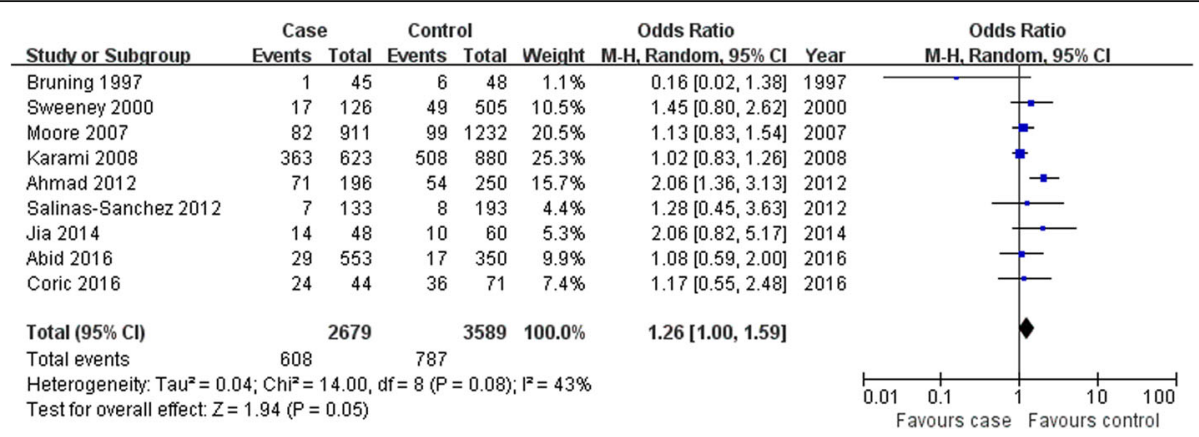

Fig. 4 Association between dual-null genotype of GSTM1-GSTT1 with RCC risk in the overall population. Cl: confidence interval

not found for GSTM1. Our results indicate that the GSTM1-null genotype does not predict the susceptibility of RCC. The sample size in our meta-analysis was larger than other meta-analyses [43, 48-51].

The average GSTT1-null genotype distribution frequency in patients with RCC was also similar to the average GSTT1-null genotype distribution frequency in the control group, indicating that the null genotype for GSTM1 is also not associated with RCC susceptibility.
For confirmation, a meta-analysis was performed and showed that there was no an association between null genotype of GSTM1 and the RCC susceptibility in the overall population, Caucasians and Asians, hospital-based controls, population-based controls. When only the high-quality studies were recruited for meta-analysis, this association was also not found. Publication bias was also tested and not found for GSTT1. Our results indicate that the GSTT1-null genotype does

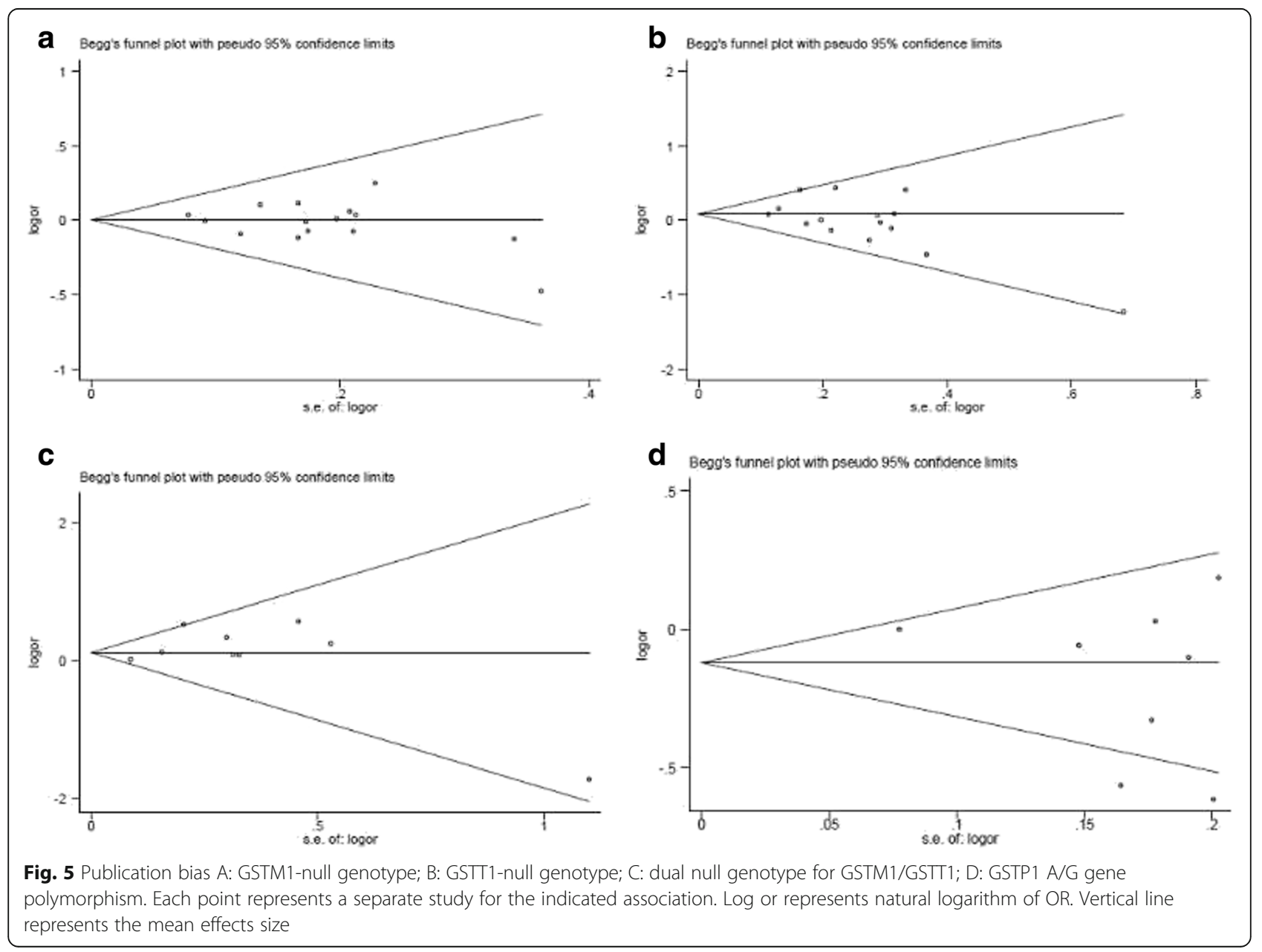


not predict the RCC susceptibility. The sample size in our meta-analysis was larger than other meta-analyses [43, 48-50].

The average GSTM1-null/GSTT1-null genotype distribution frequency in patients with RCC is slightly increased. This could indicate that the dual-null genotype, of individuals lacking both GSTM1 and GSTT1, might be associated with the susceptibility of RCC. However, further meta-analysis to detect the risk of the GSTM1-null/GSTT1-null genotype for RCC susceptibility showed no association between the GSTM1-null/ GSTT1-null genotype and RCC susceptibility in the overall population of Caucasians, compared to hospital-based controls, when only high-quality studies were recruited in the meta-analysis. However, the dual-null genotype was associated with the onset of RCC in Asians, when compared to population-based controls. There was no publication bias for this meta-analysis. As above, the sample size in our meta-analysis was larger than other meta-analyses $[48,50]$.

The association of the GSTP1 A/G gene polymorphism with the susceptibility of RCC was also characterized. The average A allele distribution frequency of GSTP1 in patients with RCC was similar when compared with that in control group, suggesting that there was no association of the GSTP1 A/G gene polymorphism with RCC susceptibility. We also conducted a meta-analysis and confirmed that the GSTP1 A/G gene polymorphism is not associated with RCC risk in the overall population of Caucasians and Asians examined, and regardless of whether controls were hospital-based or population-based, and whether high quality studies were solely used. No publication bias was found in this meta-analysis. Furthermore, the sample size in this meta-analysis was notable larger than other meta-analyses [43, 49].

We have also assessed the relationship between GSTM1 and clinical TNM stages in patients with RCC. The average GSTM1-null genotype distribution frequency in stage I + II is slightly lower when compared with that in stage $\mathrm{III}+\mathrm{IV}$ RCC $(\mathrm{I}+\mathrm{II} / \mathrm{III}+\mathrm{IV}=0.85)$. This might indicate that the GSTM1-null genotype is associated with RCC TNM stage. However, meta-analysis of the high-quality studies indicates no association of GSTM1-null genotype with clinical TNM stages of RCC is present in the overall population of Caucasians and Asians, compared to hospital-based controls. Interestingly, the GSTM1-null genotype is associated with the clinical TNM stages of RCC when the meta-analysis included controls from the population. The sample size of our meta-analysis is notable larger than other meta-analyses [29]. However, more studies are required for confirmation.

The relationship between GSTT1 and clinical TNM stages of RCC is also assessed. The average GSTT1-null genotype distribution frequency in stage I + II is notably lower when compared with that in stage III + IV RCC (I $+\mathrm{II} / \mathrm{III}+\mathrm{IV}=0.76$ ). This might indicate a lack of association of the GSTT1-null genotype with clinical TNM stages of RCC in Caucasians and Asians, when compared to population-based controls (Table 4). When only the high-quality studies were included for meta-analysis, this association was also found (Table 4). Interestingly, the GSTT1-null genotype is found to be associated with the clinical TNM stages in patients with RCC in the overall population when the meta-analysis includes hospital-based controls. The GSTT1-null genotype is also found to be associated with the clinical TNM stages in patients with RCC in the overall population, when compared to hospital-based controls, and in the meta-analysis including high quality studies. Again, the sample size of our meta-analysis is larger than a previous meta-analysis [49]. However, more studies should be performed.

Cheng et al. [50] conducted a meta-analysis that included six investigations for GSTM1, six reports for GSTT1, and four studies for the dual-null genotype for GSTM1 and GSTT1, and reported that no association was found between the GSTM1-null/GSTT1-null genotype and RCC susceptibility. The authors also performed a GSTM1-GSTT1 interaction analysis and indicated that the dual GSTM1/GSTT1-null genotype was not significantly associated with the susceptibility of RCC. Liu et al. [51] performed a meta-analysis on eight studies and showed that the GSTM1-null genotype was not significantly associated with susceptibility of RCC. Yang et al. [49] conducted a meta-analysis recruited 10 studies of GSTM1, 10 reports of GSTT1, and five studies of GSTP1, and reported that GSTM1, GSTT1 and GSTP1 gene polymorphisms were not associated with the development of the RCC disease. Jia et al. [43] performed a meta-analysis on 10 studies of GSTM1, 10 reports of GSTT1, five studies of dual GSTM1-GSTT1-null genotype, six studies of GSTP1, and concluded that GSTM1, GSTT1, and GSTP1 gene polymorphisms were not to be associated with the risk of RCC. Also, GSTM1-GSTT1 interaction analysis indicated that the dual null genotype for GSTM1/GSTT1 was notably associated with an increased RCC susceptibility. Huang et al. [48] analyzed eight studies of GSTM1, eight studies of GSTT1, three studies of GSTM1 gene polymorphism and clinical TNM stages, and four studies on GSTM1 and GSTT1 gene polymorphism and clinical TNM stages, and indicated that GSTM1 and GSTT1 gene polymorphisms were not markedly associated with RCC susceptibility in a recessive model. However, comparison of the wild-type genotype versus the dual GSTM1-GSTT1-null genotype showed a positive association with the susceptibility of RCC. The authors also identified an association of 
wild-type GSTT1 with low RCC TNM stages. A strong association between GST genotypes and polymorphism and risk of renal cancer is not there in the total population. The conclusion of all these studies is that GST genotypes and polymorphisms cannot be used as biomarkers for early diagnosis.

In this meta-analysis, there are some limitations. First, there was heterogeneity among the recruited studies for the reason that the patients and controls were from different races, and the controls were population-based or hospital-based. Second, geographic origin might affect the relationship between GSTs gene polymorphism and RCC susceptibility, and we did not conduct a sub-group analysis. Furthermore, the quality of the recruited articles was different. These factors might prevent us from drawing a more robust conclusion. In addition, although our sample size is larger than prior meta-analyses, but more original studies continue to be needed to draw a more robust conclusion. More well-designed investigations should be conducted in the future.

\section{Conclusion}

The results in this study support that there is an association of the dual GSTM1-GSTT1-null genotype with RCC susceptibility in Asians, and there is an association between the GSTT1-null genotype and clinical TNM stage of RCC in the overall population. However, more association studies are required to be conducted to further clarify these relationships.

\section{Additional file}

Additional file 1: Table S1. Scale for Quality Assessment. (DOC 44 kb)

\section{Abbreviations}

GSH: Glutathione; GST: Glutathione S-transferase; RCC: Renal cell carcinoma; TNM: Tumor node metastasis

\section{Funding}

This study was supported by Guangzhou Medical Key Discipline Construction Project.

\section{Availability of data and materials}

The datasets used and/or analyzed during the current study are available from the corresponding author on reasonable request.

\section{Authors' contributions}

TZ was in charge of conceived and designed the study. ZQZ, HYL and HZZ were responsible for collection of data and performing the statistical analysis and manuscript preparation. WJX and ZJL were responsible for checking the data. All authors were responsible for drafting the manuscript, read and approved the final version.

\section{Ethics approval and consent to participate}

Not applicable.

\section{Competing interests}

The authors declare that they have no competing interests.

\section{Publisher's Note}

Springer Nature remains neutral with regard to jurisdictional claims in published maps and institutional affiliations.

\section{Author details}

'Department of Nephrology, the Second Affiliated Hospital of Shantou University Medical College, No. 69 Dongsha Road, Shantou 515041, China. ${ }^{2}$ Department of Nephrology, Huadu District People's Hospital of Guangzhou, Southern Medical University, Guangzhou 510800, China.

Received: 10 February 2018 Accepted: 25 May 2018

Published online: 08 June 2018

\section{References}

1. Matak D, Brodaczewska KK, Szczylik C, Koch I, Myszczyszyn A, Lipiec M, Lewicki S, Szymanski L, Zdanowski R, Czarnecka AM. Functional significance of CD105-positive cells in papillary renal cell carcinoma. BMC Cancer. 2017;17(1):21.

2. Chen Z, Zhu R, Zheng J, Chen C, Huang C, Ma J, Xu C, Zhai W. Cryptotanshinone inhibits proliferation yet induces apoptosis by suppressing STAT3 signals in renal cell carcinoma. Oncotarget. 2017; 8(30):50023-33.

3. Liu L, Mao J, Wang Q, Zhang Z, Wu G, Tang Q, Zhao B, Li L, Li Q. In vitro anticancer activities of osthole against renal cell carcinoma cells. Biomed Pharmacother. 2017;94:1020-7.

4. Rabjerg M. Identification and validation of novel prognostic markers in Renal Cell Carcinoma. Dan Med J. 2017;64(10):B5339.

5. Ni W, Song E, Gong M, Li Y, Yao J, An R. Downregulation of IncRNA SDPRAS is associated with poor prognosis in renal cell carcinoma. Onco Targets Ther. 2017;10:3039-47.

6. Liu Y. The place of FDG PET/CT in renal cell carcinoma: value and limitations. Front Oncol. 2016;6:201.

7. Zhang F, Ma X, Li H, Guo G, Li P, Gu L, Li X, Chen L, Zhang X. The predictive and prognostic values of serum amino acid levels for clear cell renal cell carcinoma. Urol Oncol. 2017;35(6):392-400.

8. Kuusk T, Grivas N, de Bruijn R, Bex A. The current management of renal cell carcinoma. Minerva Med. 2017;108(4):357-69.

9. Panayiotou AG, Griffin MB, Tyllis T, Georgiou N, Bond D, Humphries SE, Nicolaides AN. Association of genotypes at the matrix metalloproteinase (MMP) loci with carotid IMT and presence of carotid and femoral atherosclerotic plaques. Vasc Med. 2013;18(5):298-306.

10. Voskarides K. Combination of 247 genome-wide association studies reveals high Cancer risk as a result of evolutionary adaptation. Mol Biol Evol. 2018;35(2):473-85

11. Voskarides K, Stefanou C, Pieri M, Demosthenous P, Felekkis K, Arsali M, Athanasiou Y, Xydakis D, Stylianou K, Daphnis E, et al. A functional variant in $\mathrm{NEPH} 3$ gene confers high risk of renal failure in primary hematuric glomerulopathies. Evidence for predisposition to microalbuminuria in the general population. PLoS One. 2017;12(3):e0174274.

12. Khella MS, Hamdy NM, Amin Al, El-Mesallamy HO. The (FTO) gene polymorphism is associated with metabolic syndrome risk in Egyptian females: a case- control study. BMC Med Genet. 2017;v18(1):101.

13. Bhat M, Parry M, Nissar S, Sameer A, Bhat I, Shah Z, Rasool R. Association of IL1 beta gene polymorphism and allograft functions in renal transplant recipients :a case control study from Kashmir Valley. BMC Nephrol. 2017;18(1):111.

14. Ferreira M, Teixeira A, Mauricio J, Lobo F, Morais A, Medeiros R. Hypoxia and renal cell carcinoma: the influence of HIF1A+1772C/T functional genetic polymorphism on prognosis. Urol Oncol. 2017;35(8):532. e525-32 e530

15. Hou Q, Li MY, Huang WT, Wei FF, Peng JP, Lou MW, Qiu JG. Association between three VEGF polymorphisms and renal cell carcinoma susceptibility: a meta-analysis. Oncotarget. 2017;8(30):50061-70.

16. Hsueh YM, Lin YC, Chen WJ, Huang CY, Shiue HS, Pu YS, Chen CH, Su CT. The polymorphism XRCC1 Arg194Trp and 8-hydroxydeoxyguanosine increased susceptibility to arsenic-related renal cell carcinoma. Toxicol Appl Pharmacol. 2017:332:1-7

17. Wang J, Shen C, Fu Y, Yu T, Song J. The associations between five polymorphisms of vascular endothelial growth factor and renal cell carcinoma risk: an updated meta-analysis. Onco Targets Ther. 2017: $10: 1725-34$. 
18. Pljesa-Ercegovac M, Savic-Radojevic A, Kravic-Stevovic T, Bumbasirevic V, Mimic-Oka J, Simic T. Co-localization of GSTP1 and JNK in transitional cell carcinoma of urinary bladder. Genet Mol Biol. 2010;33(3):460-2.

19. Pljesa-Ercegovac M, Savic-Radojevic A, Dragicevic D, Mimic-Oka J, Matic M, Sasic T, Pekmezovic T, Vuksanovic A, Simic T. Enhanced GSTP1 expression in transitional cell carcinoma of urinary bladder is associated with altered apoptotic pathways. Urol Oncol. 2011;29(1):70-7.

20. Han JH, Lee HJ, Choi HJ, Yun KE, Kang MH. Lymphocyte DNA damage and plasma antioxidant status in Korean subclinical hypertensive patients by glutathione S-transferase polymorphism. Nutr Res Pract. 2017;11(3):214-22.

21. Malik MA, Gupta V, Shukla S, Kaur J. Glutathione S-transferase (GSTM1, GSTT1) polymorphisms and JOAG susceptibility: a case control study and meta-analysis in glaucoma. Gene. 2017;628:246-52.

22. Nissar S, Sameer AS, Rasool R, Chowdri NA, Rashid F. Evaluation of deletion polymorphisms of glutathione S-transferase genes and colorectal cancer risk in ethnic Kashmiri population: a case-control study. Indian J Cancer. 2016; 53(4):524-8.

23. Mikstacki A, Skrzypczak-Zielinska M, Zakerska-Banaszak O, Tamowicz B, Skibinska M, Molinska-Glura M, Szalata M, Slomski R. Impact of CYP2E1, GSTA1 and GSTP1 gene variants on serum alpha glutathione S-transferase level in patients undergoing anaesthesia. BMC Med Genet. 2016;17(1):40.

24. Baltruskeviciene E, Kazbariene B, Aleknavicius E, Krikstaponiene A, Venceviciene L, Suziedelis K, Stratilatovas E, Didziapetriene J. Changes of reduced glutathione and glutathione S-transferase levels in colorectal cancer patients undergoing treatment. Tumori. 2017; https://doi.org/10. 5301/tj.5000674

25. Muguruma N, Okamoto K, Nakagawa T, Sannomiya K, Fujimoto S, Mitsui Y, Kimura T, Miyamoto H, Higashijima J, Shimada M, et al. Molecular imaging of aberrant crypt foci in the human colon targeting glutathione Stransferase P1-1. Sci Rep. 2017;7(1):6536.

26. Wang W, Liu F, Wang C, Tang Y, Jiang Z. Glutathione S-transferase A1 mediates nicotine-induced lung cancer cell metastasis by promoting epithelial-mesenchymal transition. Exp Ther Med. 2017;14(2):1783-8.

27. Della Torre $\mathrm{OH}$, Paes LA, Henriques TB, de Mello MP, EHRV C, Dalgalarrondo $P$, Guerra-Júnior G, Santos-Júnior AD. Dopamine D2 receptor gene polymorphisms and externalizing behaviors in children and adolescents. BMC Med Genet. 2018;19(1):65.

28. Yao J, Qi XL, Zhang Y. The Alu-insertion progesterone receptor gene polymorphism is not associated with breast cancer: a meta-analysis. BMC Med Genet. 2018;19(1):16.

29. Thakkinstian A, McEvoy M, Minelli C, Gibson P, Hancox B, Duffy D, Thompson J, Hall I, Kaufman J, Leung TF, et al. Systematic review and metaanalysis of the association between \{beta\}2-adrenoceptor polymorphisms and asthma: a HuGE review. Am J Epidemiol. 2005;162(3):201-11.

30. Begg CB, Mazumdar M. Operating characteristics of a rank correlation test for publication bias. Biometrics. 1994;50(4):1088-101.

31. Egger M, Davey Smith G, Schneider M, Minder C. Bias in meta-analysis detected by a simple, graphical test. BMJ. 1997;315(7109):629-34.

32. Bruning $T$, Lammert M, Kempkes $M$, Thier R, Golka K, Bolt HM. Influence of polymorphisms of GSTM1 and GSTT1 for risk of renal cell cancer in workers with long-term high occupational exposure to trichloroethene. Arch Toxicol. 1997;71(9):596-9.

33. Longuemaux S, Delomenie C, Gallou C, Mejean A, Vincent-Viry M, Bouvier R, Droz D, Krishnamoorthy R, Galteau MM, Junien C, et al. Candidate genetic modifiers of individual susceptibility to renal cell carcinoma: a study of polymorphic human xenobiotic-metabolizing enzymes. Cancer Res. 1999; 59(12):2903-8

34. Sweeney C, Farrow DC, Schwartz SM, Eaton DL, Checkoway H, Vaughan TL. Glutathione S-transferase M1, T1, and P1 polymorphisms as risk factors for renal cell carcinoma: a case-control study. Cancer Epidemiol Biomark Prev. 2000;9(4):449-54.

35. Buzio L, De Palma G, Mozzoni P, Tondel M, Buzio C, Franchini I, Axelson O, Mutti A. Glutathione S-transferases M1-1 and T1-1 as risk modifiers for renal cell cancer associated with occupational exposure to chemicals. Occup Environ Med. 2003;60(10):789-93.

36. Moore LE, Brennan P, Karami S, Hung RJ, Hsu C, Boffetta P, Toro J, Zaridze $D$, Janout $V$, Bencko V, et al. Glutathione S-transferase polymorphisms, cruciferous vegetable intake and cancer risk in the central and eastern European kidney Cancer study. Carcinogenesis. 2007;28(9):1960-4.

37. Wiesenhutter B, Selinski S, Golka K, Bruning T, Bolt HM. Re-assessment of the influence of polymorphisms of phase-Il metabolic enzymes on renal cell cancer risk of trichloroethylene-exposed workers. Int Arch Occup Environ Health. 2007;81(2):247-51.

38. Karami S, Boffetta P, Rothman N, Hung RJ, Stewart T, Zaridze D, Navritalova $M$, Mates $D$, Janout $V$, Kollarova $H$, et al. Renal cell carcinoma, occupational pesticide exposure and modification by glutathione S-transferase polymorphisms. Carcinogenesis. 2008;29(8):1567-71.

39. Coric V, Pljesa-Ercegovac M, Matic M, Krivic B, Suvakov S. The role of GSTM1 and GSTT1 polymorphism in patients with renal cell carcinoma. J Med Biochemist. 2010;29(3):204-10.

40. De Martino M, Klatte T, Schatzl G, Remzi M, Waldert M, Haitel A, Stancik I, Kramer G, Marberger M. Renal cell carcinoma Fuhrman grade and histological subtype correlate with complete polymorphic deletion of glutathione S-transferase M1 gene. J Urol. 2010;183(3):878-83.

41. Ahmad ST, Arjumand W, Seth A, Kumar Saini A, Sultana S. Impact of glutathione transferase $\mathrm{M} 1, \mathrm{~T} 1$, and $\mathrm{P} 1$ gene polymorphisms in the genetic susceptibility of north Indian population to renal cell carcinoma. DNA Cell Biol. 2012;31(4):636-43.

42. Salinas-Sanchez AS, Sanchez-Sanchez F, Donate-Moreno MJ, Rubio-delCampo A, Serrano-Oviedo L, Gimenez-Bachs JM, Martinez-Sanchiz C, SeguraMartin M, Escribano J. GSTT1, GSTM1, and CYP1B1 gene polymorphisms and susceptibility to sporadic renal cell cancer. Urol Oncol. 2012;30(6):864-70.

43. Jia CY, Liu YJ, Cong XL, Ma YS, Sun R, Fu D, Lv ZW. Association of glutathione S-transferase M1, T1, and P1 polymorphisms with renal cell carcinoma: evidence from 11 studies. Tumour Biol. 2014;35(4):3867-73.

44. Coric VM, Simic TP, Pekmezovic TD, Basta-Jovanovic GM, Savic Radojevic AR, Radojevic-Skodric SM, Matic MG, Dragicevic DP, Radic TM, Bogdanovic LM et al. Combined GSTM1-null, GSTT1-active, GSTA1 low-activity and GSTP1variant genotype is associated with increased risk of clear cell renal cell carcinoma. PLoS One. 2016;11(8):e0160570.

45. Abid A, Ajaz S, Khan AR, Zehra F, Hasan AS, Sultan G, Mohsin R, Hashmi A, Niamatullah N, Rizvi SA et al. Analysis of the glutathione S-transferase genes polymorphisms in the risk and prognosis of renal cell carcinomas. Casecontrol and meta-analysis. Urol Oncol 2016; 34(9):419 e411-9 e412.

46. Coric VM, Simic TP, Pekmezovic TD, Basta-Jovanovic GM, Savic-Radojevic AR, Radojevic-Skodric SM, Matic MG, Suvakov SR, Dragicevic DP, Radic TM, et al. GSTM1 genotype is an independent prognostic factor in clear cell renal cell carcinoma. Urol Oncol. 2017:35(6):409-17.

47. Wang G, Hou J, Ma L, Xie J, Yin J, Xu D, Chang W, Tan X, Su T, Zhang H, et al. Risk factor for clear cell renal cell carcinoma in Chinese population: a case-control study. Cancer Epidemiol. 2012;36(2):177-82.

48. Huang W, Shi H, Hou Q, Mo Z, Xie X. GSTM1 and GSTT1 polymorphisms contribute to renal cell carcinoma risk: evidence from an updated metaanalysis. Sci Rep. 2015;5:17971.

49. Yang X, Long S, Deng J, Deng T, Gong Z, Hao P. Glutathione Stransferase polymorphisms (GSTM1, GSTT1 and GSTP1) and their susceptibility to renal cell carcinoma: an evidence-based meta-analysis. PLoS One. 2013;8(5):e63827.

50. Cheng HY, You HY, Zhou TB. Relationship between GSTM1/GSTT1 null genotypes and renal cell carcinoma risk: a meta-analysis. Ren Fail. 2012; 34(8):1052-7.

51. Liu R, Wang XH, Liu L, Zhou Q. No association between the GSTM1 null genotype and risk of renal cell carcinoma: a meta-analysis. Asian Pac J Cancer Prev. 2012;13(7):3109-12.

\section{Ready to submit your research? Choose BMC and benefit from:}

- fast, convenient online submission

- thorough peer review by experienced researchers in your field

- rapid publication on acceptance

- support for research data, including large and complex data types

- gold Open Access which fosters wider collaboration and increased citations

- maximum visibility for your research: over $100 \mathrm{M}$ website views per year

At BMC, research is always in progress.

Learn more biomedcentral.com/submissions 